\title{
Evaluation of a counter-flow microchannel heat exchanger performance with air-water vapor mixture to liquid water
}

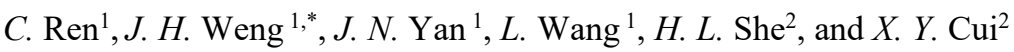

${ }^{1}$ School of Energy\& Mechanical Engineering, Shanghai University of Electric Power, Shanghai 200090

${ }^{2}$ School of Energy and Power Engineering, University of Shanghai for Science and Technology, Shanghai 200093

\begin{abstract}
Given its configuration and operation conditions, the performance of a counter-flow microchannel heat exchanger (MCHX) is evaluated through detailed calculations. The fluids, both liquid water and air, are considered as continuum flow flowing in microchannels. The MCHX has 59 sheets, and each sheet has 48 microchannels. The microchannels for both fluids have the same cross section of $0.8 \mathrm{~mm} \times 1 \mathrm{~mm}$ and same length of $200 \mathrm{~mm}$. Log mean temperature difference method is adopted for this evaluation. Using appropriate equations, the properties of air-water vapor mixture are calculated based on that of the two components. Given the inlet temperature for liquid water $\left(35^{\circ} \mathrm{C}\right)$ and air $\left(170^{\circ} \mathrm{C}\right)$, the calculated outlet temperature for both fluids are $55.5^{\circ} \mathrm{C}$ and $43.3^{\circ} \mathrm{C}$, respectively. The results also show that the air at the outlet is saturated. The overall heat transfer coefficient reaches $100 \mathrm{~W} / \mathrm{m}^{2} \cdot \mathrm{K}$, which is much higher than that of conventional heat exchanger with similar fluid combinations.
\end{abstract}

\section{Introduction}

Microchannel heat exchangers (MCHXs) have been increasingly attractive in many applications such as energy system, electronic cooling, fuel cell automobiles, etc.. They have advantages of small size, light in weight, less materials, and high heat transfer coefficients. In addition, they have very high surface area to volume ratios. Heat exchangers are usually critical components in energy systems and more and more MCHXs are used due to their advantages. In a waste heat recovery and energy conversion system [1], a nominal $10.6 \mathrm{KW}$ crosscounter MCHX was designed and fabricated. Oil was used to recover the heat of the exhaust gases from a diesel engine in a MCHX. The microchannel is $2 \mathrm{~mm}$ in width and $0.8 \mathrm{~mm}$ in depth on the exhaust side, and $1.5 \mathrm{~mm}$ in width and $0.15 \mathrm{~mm}$ in depth on the oil side. The MCHX was fabricated by photochemical etching and diffusion brazing processes. In another application, D. A. Kromer et al. [2] designed, fabricated and evaluated a type of stainless steel MCHXs used in a new reactor system. The MCHXs were arranged in groups in the system for heat exchanging between the primary and secondary coolant. The cross-section of the channels for both coolant is close to a semi-circular, with a flat bottom. The height and width of the channel are $0.635 \mathrm{~mm}$ and $1.397 \mathrm{~mm}$, respectively. The photochemical etching and diffusion bonding processes were used to fabricate the MCHXs. For high temperature gasgas heat exchanging, a ceramic counter-counter flow MCHX was designed, fabricated and evaluated [3]. Ceramic materials allow the MCHX to be operated at very high temperature or in a harsh chemical environment. The MCHX was tested with hot air inlet temperature up to $750^{\circ} \mathrm{C}$. The microchannel is approximately $550 \mu \mathrm{m}$ in height and $2.8 \mathrm{~mm}$ in width.

MCHXs are also attractive to high-heat-flux thermal management. A copper alloy microchannel heat exchanger with overall dimensions of $1 \mathrm{~cm} \times 1 \mathrm{~cm} \times 1 \mathrm{~cm}$ was designed and fabricated using micro-electrodischarge machining( $\mu \mathrm{EDM})$ [4]. The MCHX was used to remove the heat from a closed-loop flow of refrigerant R245fa by air. The flow passage for air is circular and has a diameter of $520 \mu \mathrm{m}$, while that for refrigerant R245fa is rectangular and has a size of $0.5 \mathrm{~mm} \times 2 \mathrm{~mm}$. The rate of heat transfer for the cross-flow MCHX reaches up to $60 \mathrm{~W}$.

In this paper, a MCHX with air-water vapor mixture as hot fluid and liquid water as cold fluid is evaluated by detailed calculations. The air-water vapor mixture is cooled by liquid water. Given inlet temperature for both fluids, the heat load is calculated through an iteration process. It is found water vapor in the air starts to condense at somewhere along the flow passage and the air at the outlet is saturated. Improvements for the MCHX design are also discussed.

\section{MCHX configuration}

The MCHX consists of 59 sheets, alternating between air and liquid water sheets (Fig. 1). Each sheet has 48 microchannels. The cross-section of the microchannel for both fluids has a same size of $0.8 \mathrm{~mm} \times 1 \mathrm{~mm}$. The length of the microchannel for both fluids also is same, which is $200 \mathrm{~mm}$ (Fig. 2). The two fluids flow in the opposite direction, which makes the MCHX a counter

\footnotetext{
* Corresponding author: jhweng@shiep.edu.cn
} 
flow heat exchanger. The materials of the MCHX is stainless steel, and the microchannel is micro-fabricated on each sheet.

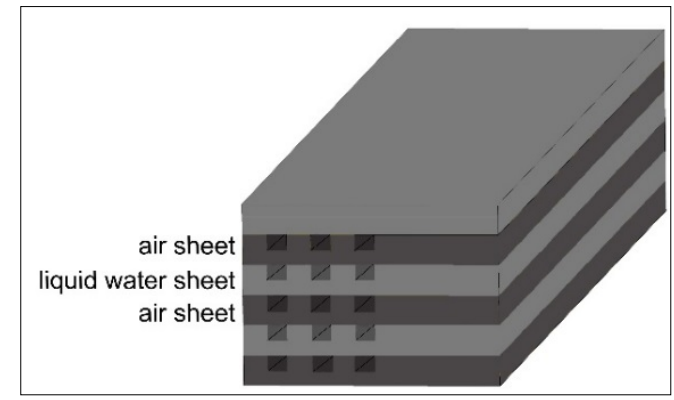

Fig. 1. Sheet arrangement for MCHX.

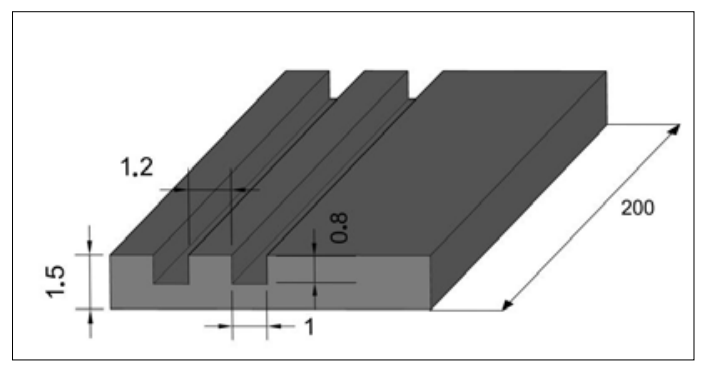

Fig. 2. Sheet arrangement for MCHX.

Table 1. MCHX channel dimensions.

\begin{tabular}{ll}
\hline \multicolumn{1}{c}{ Parameter } & Value \\
\hline Channel height $/ \mathrm{mm}$ & 0.8 \\
Channel width/mm $/ \mathrm{mm}$ & 1.0 \\
Channel length/mm & 200 \\
Hydraulic diameter $/ \mathrm{mm}$ & 0.8889 \\
\hline
\end{tabular}

\section{Performance evaluation method}

\subsection{Flow regime}

The flow in microchannel can be classified into 4 regimes according to the Knudsen number $K n$. For $K n$ less than 0.001, the flow is a continuum flow and can be accurately modeled by N-S equations with classical noslip boundary conditions. And correlations developed for conventional macrochannels are mostly valid for microchannel predictions, although sometimes divergences were found. In this study, the pressure of air flow is around $1 \mathrm{~atm}$, and the inlet temperature is $170^{\circ} \mathrm{C}$. Using the below equation [5]:

$$
K n=\frac{\lambda}{L}
$$

where $k_{2}=1.277$, and

$$
\lambda=k_{2} \frac{\mu}{\rho \sqrt{R T}}
$$

the calculated $\mathrm{Kn}$ number is 0.000123 in this study, which is less than 0.001 for the air flowing in micrchannels. Correlations for macrochannel flow are used for the calculation of air stream below.

\subsection{Thermal properties of air-water vapor mixture}

The air stream is cooled while heating the water in the MCHX. The air stream consists of dry air and water vapor, and it is a mixture of the two components. The dynamic viscosity and thermal conductivity are calculated with the following equations [6]:

$$
\begin{aligned}
& \mu_{a}=\frac{x_{d a} \mu_{d a}}{x_{d a}+x_{v} \phi_{12}}+\frac{x_{v} \mu_{v}}{x_{v}+x_{d a} \phi_{21}} \\
& \lambda_{a}=\frac{x_{d a} \lambda_{d a}}{x_{d a}+x_{v} \phi_{12}}+\frac{x_{v} \lambda_{v}}{x_{v}+x_{d a} \phi_{21}}
\end{aligned}
$$

where,

$$
\phi_{i j}=\frac{\left[1+\left(\mu_{i} / \mu_{j}\right)^{1 / 2}\left(M_{j} / M_{i}\right)^{1 / 4}\right]^{2}}{\left[8\left(1+M_{i} / M_{j}\right)\right]^{1 / 2}}
$$

\subsection{Overall heat transfer coefficient}

As the thermal conductivity of the stainless steel is relatively high, the thermal resistance of the solid wall of the MCHX is neglected for simplicity in this study. Also as the areas of the channels for both fluids are equal, the overall heat transfer coefficient can be written as:

$$
\frac{1}{U}=\frac{1}{h_{c a}}+\frac{1}{h_{c w}}
$$

For fully developed laminar flow in rectangular channel(constant wall temperature) [5],

$$
\begin{aligned}
N u= & 7.541\left(1-2.610 \alpha+4.970 \alpha^{2}\right. \\
& \left.-5.119 \alpha^{3}+2.702 \alpha^{4}-0.548 \alpha^{5}\right)
\end{aligned}
$$

where $\alpha$ is the channel aspect ratio $a / b$. And convection heat transfer coefficients for both fluids are calculated using the above equation.

\subsection{Heat transfer calculation}

Given the inlet temperature of air and liquid water and the MCHX configuration, a heat transfer rate $Q^{\prime}$ is first assumed for the calculation. Then the outlet temperature of the liquid water and air-water vapor mixture are determined from below equations [7-8]:

$$
\begin{gathered}
Q_{w}=q_{m w} C_{p w}\left(t_{w o}-t_{w i}\right) \\
Q_{a}=q_{m a}\left(h_{a o}-h_{a i}\right)-q_{m c w} h_{w}
\end{gathered}
$$

Equation (9) is used as the air is already saturated at the outlet, and water-vapor condensation happens during 
the cooling of the air. The enthalpy of air per unit mass of dry air is

$$
h=h_{a}+d h_{v}
$$

After the determination of outlet temperature, the log mean temperature difference is calculated (for counter flow heat exchanger):

$$
\Delta t_{m}=\frac{\Delta t_{\max }-\Delta t_{\min }}{\ln \frac{\Delta t_{\max }}{\Delta t_{\min }}}
$$

The heat transfer rate between liquid water and airwater vapor is calculated:

$$
Q=U A \Delta t_{m}
$$

The calculated heat transfer rate $Q$ is then compared with the assumed $Q^{\prime}$. If the two are close (e.g. less than $5 \%$ ), the iteration process is terminated. Otherwise a new $Q^{\prime}$ is assumed and the iteration process continues.

\subsection{Pressure drop calculation}

For fully developed laminar flow in microchannels, as both fluids are considered as continuum flow, the Fanning friction factor can be calculated from the below equation [5]:

$$
\begin{aligned}
f \operatorname{Re}= & 24\left(1-1.3553 \alpha+1.9467 \alpha^{2}-1.7012 \alpha^{3}\right. \\
& \left.+0.9564 \alpha^{4}-0.2574 \alpha^{5}\right)
\end{aligned}
$$

The pressure drop for both fluids are

$$
\Delta p=\frac{2 f \rho u^{2} L}{D_{h}}
$$

\section{Results and discussions}

For the MCHX in this study, the inlet temperature of air is $170^{\circ} \mathrm{C}$, with a humidity ratio $150 \mathrm{~g}$ water vapor per $\mathrm{kg}$ dry air. The inlet temperature of liquid water is $35^{\circ} \mathrm{C}$. The two fluids flow in a counter-flow condition. Using the above method, the outlet temperature for both liquid water and air, as well as the heat load of the MCHX are obtained through the iteration process. The evaluation results are shown in Table 2 . The outlet temperature for liquid water and air are $55.5^{\circ} \mathrm{C}$ and $43.3^{\circ} \mathrm{C}$, respectively. And the heat load of the MCHX is about $4.1 \mathrm{~kW}$. The air at the outlet is saturated and certain amount of water vapor is condensed. The pressure drop for liquid water and air are $0.202 \mathrm{kPa}$ and $1.884 \mathrm{kPa}$, respectively. Fluid properties are summarized in Table 3 . The design of the MCHX has much room for optimization. For example, the convection heat transfer coefficient of the air side is much lower than that of the liquid water side, and increasing the convective heat transfer coefficient of the air side could efficiently increase the overall heat transfer coefficient, which can improve the MCHX overall performance. This could be done by turning the air into turbulent flow, etc..

Table 2. Evaluation results summary.

\begin{tabular}{ll}
\hline & Value \\
\hline Air side & 12.49 \\
Velocity $/ \mathrm{m} \cdot \mathrm{s}^{-1}$ & 484 \\
$\mathrm{Re}$ & 3.01 \\
$\mathrm{Nu}$ & 105.0 \\
Convection heat transfer coefficient $/ \mathrm{W} \cdot \mathrm{m}^{-2} \cdot \mathrm{K}^{-1}$ & 43.3 \\
Outlet temperature $/{ }^{\circ} \mathrm{C}$ & 4.205 \\
Heat transfer rate from air side $/ \mathrm{kW}$ & 1.884 \\
Pressure drop $/ \mathrm{kPa}$ & \\
Liquid water side & 0.045 \\
Velocity $/ \mathrm{m} \cdot \mathrm{s}^{-1}$ & 65 \\
Re & 3.01 \\
Nu & 2146.5 \\
Convection heat transfer coefficient $/ \mathrm{W} \cdot \mathrm{m}^{-2} \cdot \mathrm{K}^{-1}$ & 55.5 \\
Outlet temperature $/{ }^{\circ} \mathrm{C}$ & 4.205 \\
Heat transfer rate from water side $/ \mathrm{kW}$ & 0.202 \\
Pressure drop $/ \mathrm{kPa}$ & 100.1 \\
Overall heat transfer coefficient $/ \mathrm{W} \cdot \mathrm{m}^{-2} \cdot \mathrm{K}^{-1}$ & 40.5 \\
Mean temperature difference $/{ }^{\circ} \mathrm{C}$ & 4.054 \\
Heat transfer rate $/ \mathrm{kW}$ & \\
\hline
\end{tabular}


Table 3. Fluid properties summary.

Air side (mixture of dry air and water vapor)

Density at inlet $/ \mathrm{kg} \cdot \mathrm{m}^{-3}$

Density at outlet $/ \mathrm{kg} \cdot \mathrm{m}^{-3}$

Thermal conductivity at inlet $/ \mathrm{W} \cdot \mathrm{m}^{-1} \cdot \mathrm{K}^{-1}$

Thermal conductivity at outlet $/ \mathrm{W} \cdot \mathrm{m}^{-1} \cdot \mathrm{K}^{-1}$

Dynamic viscosity at inlet $/ \mathrm{kg} \cdot \mathrm{m}^{-1} \cdot \mathrm{s}^{-1}$

Dynamic viscosity at inlet $/ \mathrm{kg} \cdot \mathrm{m}^{-1} \cdot \mathrm{s}^{-1}$

Liquid water side

Density at inlet $/ \mathrm{kg} \cdot \mathrm{m}^{-3}$

Density at outlet $/ \mathrm{kg} \cdot \mathrm{m}^{-3}$

Thermal conductivity at inlet $/ \mathrm{W} \cdot \mathrm{m}^{-1} \cdot \mathrm{K}^{-1}$

Thermal conductivity at outlet $/ \mathrm{W} \cdot \mathrm{m}^{-1} \cdot \mathrm{K}^{-1}$

Dynamic viscosity at inlet $/ \mathrm{kg} \cdot \mathrm{m}^{-1} \cdot \mathrm{s}^{-1}$

Dynamic viscosity at inlet $/ \mathrm{kg} \cdot \mathrm{m}^{-1} \cdot \mathrm{s}^{-1}$

\section{Conclusions}

The performance of a counter-flow MCHX is evaluated and the heat load and pressure drops of both water and air side are obtained. The air is cooled while the liquid water is heated. Based on the Kn number, the air flow can be considered as continuum flow, so correlations for macrochannel flow are used for the calculation. Thermal properties of the air stream, which is a mixture of dry air and water vapor, are calculated with the properties of the two components. The air at the outlet is saturated and
Value

1.0466

0.0357

0.0264

$2.2906 \times 10^{-5}$

$1.8540 \times 10^{-5}$

994.0

985.2

0.623

0.649

$7.20 \times 10^{-4}$

$5.04 \times 10^{-4}$

certain amount of water vapor is condensed. Comparing with the convection heat transfer coefficient of water side, the convection heat transfer coefficient of air side is relative low. Configurations of the MCHX should be optimized to improve the heat exchanger performance. When water is replaced by methanol-water solution, the MCHX can be used as a heat exchanger in the power system of fuel cell automobile. MCHX, as highly compact heat exchanger, can be used in various applications, such as energy system, automobile, etc.. The MCHXs are expected to have wide applications in industry due to their advantages.

\section{Nomenclature}

\begin{tabular}{|c|c|}
\hline Variables & $\alpha:$ aspect ratio, $\mathrm{a} / \mathrm{b}$ \\
\hline A: area, $m^{2}$ & $\rho:$ density, $\mathrm{kg} / \mathrm{m}^{3}$ \\
\hline a: channel height, $\mathrm{m}$ & $\begin{array}{l}\lambda: \text { thermal conductivity, } \mathrm{W} / \mathrm{m}^{2} \cdot \mathrm{K} ; \\
\text { mean free path, } \mathrm{m}\end{array}$ \\
\hline $\mathrm{b}:$ channel width, $\mathrm{m}$ & $\mu$ : dynamic viscosity, $\mathrm{kg} / \mathrm{m} \cdot \mathrm{s}$ \\
\hline \multicolumn{2}{|l|}{$\mathrm{C}_{\mathrm{p}}:$ specific heat, $\mathrm{J} / \mathrm{kg} \cdot \mathrm{K}$} \\
\hline \multicolumn{2}{|l|}{$\mathrm{D}_{\mathrm{h}}:$ hydraulic diameter, $\mathrm{m}$} \\
\hline \multicolumn{2}{|l|}{$\mathrm{d}$ : specific humidity, $\mathrm{kg} / \mathrm{kg}$} \\
\hline f: Fanning friction factor & Subscrips \\
\hline h: specific enthalpy, J/kg; & a: air side \\
\hline $\mathrm{h}_{\mathrm{c}}$ : convection heat transfer coefficient, $\mathrm{W} / \mathrm{m}^{2} \cdot \mathrm{K}$ & da: dry air \\
\hline Kn: Knuden number & i: inlet \\
\hline L: channel length,m & $\mathrm{i}, \mathrm{j}$ : component \\
\hline M: molar mass, $\mathrm{kg} / \mathrm{kmol}$ & o: outlet \\
\hline Nu: Nusselt number & v: water vapor \\
\hline$\Delta \mathrm{p}:$ pressure drop, $\mathrm{Pa}$ & w: water side \\
\hline Q: heat transfer rate, $\mathrm{W}$ & o: outlet \\
\hline \multicolumn{2}{|l|}{$\mathrm{q}_{\mathrm{m}}$ : mass flow rate, $\mathrm{kg} / \mathrm{s}$} \\
\hline \multicolumn{2}{|l|}{$\mathrm{R}:$ Gas constant, $\mathrm{J} / \mathrm{kg} \cdot \mathrm{K}$} \\
\hline \multicolumn{2}{|l|}{ Re: Reynolds number } \\
\hline \multicolumn{2}{|l|}{ T: temperature, $\mathrm{K}$} \\
\hline \multicolumn{2}{|l|}{ t: temperature, ${ }^{\circ} \mathrm{C}$} \\
\hline \multicolumn{2}{|l|}{$\Delta \mathrm{t}$ : temperature difference, ${ }^{\circ} \mathrm{C}$} \\
\hline \multicolumn{2}{|l|}{$\mathrm{U}$ : overall heat transfer coefficient, $\mathrm{W} / \mathrm{m}^{2} \cdot \mathrm{K}$} \\
\hline \multicolumn{2}{|l|}{$\mathrm{u}:$ velocity, $\mathrm{m} / \mathrm{s}$} \\
\hline $\mathrm{x}$ : mole fraction & \\
\hline
\end{tabular}

This work is supported by Natural Science Foundation of Shanghai, Grant No. 14ZR1429100. 


\section{References}

1. J. Yih, H. Wang, Energy Convers. Manage. 204, 1$29(2020)$

2. D. A. Kromer, A. J. Huning, S. Garimella, Ann, Nucl. Energy, 145, 1-18(2020)

3. R. J. Kee, B. B. Almand, J. M. Blasi, et al., Appl. Therm. Eng., 31, 2004-2012(2011)

4. B. Kwon, N. I. Maniscalco, A. M. Jacobi, et al., Int. J. Heat Mass Transfer, 118, 1276-1283(2018)

5. S. G. Kandlikar, S. Garimella, D. Li, et al., Heat transfer and fluid flow in minichannels and microchannels (Elsevier Ltd., Oxford, 2006)

6. J. S. Tong, Thermophysical properties of fluids: basic theory and calculations (China Petrochemical Press, Beijing, 2008)

7. F. P. Incropera, D. P. DeWitt, Introduction to heat transfer (John Wiley\&Sons, Inc., New York, 1985)

8. Y. A. Cengel, M. A. Boles, Thermodynamics: an engineering approach (New York: McGraw-Hill Companies, Inc., New York, 2002) 